\title{
Building Capacity in Implementation Science for Cancer Prevention and Control Through a Research Network Scholars Program
}

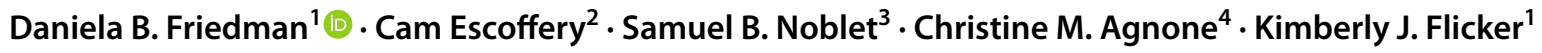

Accepted: 30 June 2021 / Published online: 9 July 2021

(c) American Association for Cancer Education 2021

\begin{abstract}
Building capacity of researchers and practitioners in the dissemination and implementation (D\&I) of evidence-based interventions is greatly needed to improve cancer prevention and control. A diverse workforce trained in D\&I science is critical for improving cancer outcomes and reducing cancer-related health disparities. The US Centers for Disease Control and Prevention's (CDC) Cancer Prevention and Control Research Network (CPCRN) Scholars Program aimed at training students, researchers, and practitioners in D\&I for cancer prevention and control launched in 2021. The purpose of this paper is to describe the creation of the training program, curriculum, and evaluation plans, and to present the baseline results and lessons learned. CPCRN investigator and partner input and formative interviews $(\mathrm{n}=16)$ with assistant professors, postdoctoral fellow, doctoral and undergraduate students, and a program manager guided development of the program. Twenty of 24 applicants were accepted into the inaugural year of the program. The majority of accepted scholars identified as female (80\%) and were graduate students (50\%). Thirty-five percent were of racially diverse backgrounds. Most self-rated their previous D\&I experience and competencies at a beginner level. The multi-step approach used for development of this training program and lessons learned will be helpful for others collaborating on preparing the research and practice workforce in D\&I science.
\end{abstract}

Keywords Training $\cdot$ Implementation science $\cdot$ Cancer disparities $\cdot$ Professional development $\cdot$ Research network . Mentorship

\section{Background}

The USA spent $\$ 150.8$ billion on cancer care in 2018 and this cost is expected to rise according to projections from the International Agency of Research on Cancer [1]. As both the national and global populations age, global cancer cases

Daniela B. Friedman

dbfriedman@sc.edu

1 Department of Health Promotion, Education, and Behavior and Office for the Study of Aging, Arnold School of Public Health, University of South Carolina, 915 Greene Street, Columbia, SC 29208, USA

2 Department of Behavioral, Social, and Health Education Sciences, Rollins School of Public Health, 1518 Clifton Road, Atlanta, GA 30322, USA

3 Department of Health Promotion, Education, and Behavior and Prevention Research Center, Arnold School of Public Health, University of South Carolina, 915 Greene Street, Columbia, SC 29208, USA

4 Emory Rollins School of Public Health, 1518 Clifton Road, Atlanta, GA 30322, USA and deaths are expected to increase along with the cost of care and treatment. This growing public health challenge has prompted the World Bank to advise countries it finances to be both efficient and effective at addressing cancer prevention and control [2]. Yet with evidence-based research taking on average 17 years to matriculate through clinical research to patient practice [3], there is an even greater urgency for dissemination and implementation (D\&I) science research to reach practitioners [4-6]. At its core, D\&I science is understanding how to effectively promote the systematic uptake of evidence-based interventions and/or practices and translate them into the real world to maximize positive health behaviors and outcomes $[7,8]$.

Cancer-focused mentored training programs have been implemented for clinicians and medical students [9-12] and postdoctoral fellows and/or early career scientists [13-17] to increase D\&I competencies. Some training programs are degree seeking while others are one-time offerings or episodic depending on the sponsoring organization. There is great variability in the focus and reporting of findings from such capacity-building programs [18]. The dissemination 
and sharing of detailed processes used for these training programs would be beneficial for those planning programming in different settings and across different contexts [19]. Since D\&I is a relatively young field and there are many cancerrelated health disparities, there is a tremendous need to build capacity in this area $[20,21]$. Creating a pipeline of diverse cancer-focused research scholars and practitioners is needed to meet the growing demand of translating cancer research to timely practice.

The Cancer Prevention and Control Research Network (CPCRN) is a national network of academic, public health, and community partners who are charged to "reduce the burden of cancer, especially among those disproportionately affected" [22]. Eight funded centers work with the Centers for Disease Control and Prevention (CDC) and the National Cancer Institute (NCI) to expedite evidence-based interventions and strategies to reduce cancer and to build a workforce in cancer D\&I research [22]. In recognition of the need to increase the pipeline of student, researcher, and practitioner scholars focused on D\&I science, CPCRN investigators proposed a cross-center workgroup that would provide mentored training in this area. The CPCRN Scholars Program is guided by a prior CDC-funded student-focused scholars program focused on cognition aging [23] and an in-depth formative evaluation. The purpose of this paper is to describe the process of creating a training program in D\&I for cancer prevention and control among CPCRN students, researchers, and practitioner scholars, the curriculum, and evaluation plan. In addition, we present the baseline results of selected scholars.

\section{Methods}

The CPCRN Scholars Workgroup, consisting of faculty, researchers, and students from six CPCRN centers, affiliate members, and federal agency partners, collaborated on development of a program aimed to train students (undergraduate through doctoral), postdoctoral fellows, junior faculty, practitioners, and health professionals in D\&I science focused on cancer prevention and control and health equity. A multi-step approach was used for program development.

\section{Program Conceptualization}

The idea for the Scholars Program was proposed at the annual meeting of the CPCRN in January 2020 at which 50 members and affiliates attended. The idea was guided by a student-focused scholars program that was developed for the CDC-funded Healthy Brain Research Network (HBRN; [23]). The HBRN aimed to train racially/ethnically, geographically, and gender-diverse students in Alzheimer's disease research through mentored, collaborative research.
Following the CPCRN annual meeting, CPCRN investigators interested in leading the Scholars Workgroup (CE and DBF), worked collaboratively with interested CPCRN investigators, affiliates, and federal agency partners to develop a workgroup charter that presented the main goals of the workgroup and potential deliverables with clear timeline. In Spring 2020, the charter was presented at a CPCRN steering committee meeting that consisted of CPCRN principal investigators, project directors, and federal agency partners. The charter was approved at that meeting and Scholar Workgroup members $(n=\sim 25)$ started meeting monthly to develop program components. The workgroup consisted of six CPCRN centers, two affiliate members, and NCI partners.

\section{Curriculum Development}

Guided by the model developed for the HBRN Scholars Program, the Workgroup began to consider training components for the program that would prepare them for D\&I work in cancer prevention and control. Workgroup members wanted to ensure that tracks were created and that program components were tailored for different groups of scholars, in particular, students, postdoctoral fellows/faculty researchers, and practitioners. Three tracks were created that included foundational readings about the CPCRN network, implementation science and health equity; interactive webinars and discussion; and an option of completing one of two curricula - the CPCRN network-developed Putting Public Health Evidence in Action (PPHEA) [24] and the NCI-developed Training Institute for Dissemination and Implementation Research in Cancer (TIDIRC) program [25]. PPHEA supports community program planners and health educators in developing skills in using evidence-based approaches and learning about new tools for planning and evaluating community health interventions. It is a self-paced curriculum with activities and tools. TIDIRC provides participants with foundational information and resources for conducting D\&I research with a focus on cancer prevention and control. Online training materials are open access (see Table 1 for an overview of the CPCRN Scholars Program curriculum by track).

\section{Formative Research to Guide Program Development}

In order to gain input from potential scholars and to ensure the program we developed met the needs of CPCRN scholars, Workgroup members emailed student, faculty/ researcher, and practitioner contacts from CPCRN centers to invite them to participate in a 30-min interview with workgroup project co-directors (CA and SB). Workgroup members co-developed the interview guide. Questions can be found in Table 2. Following the open coding of Scholar interview transcripts in Microsoft Excel [26], findings were 


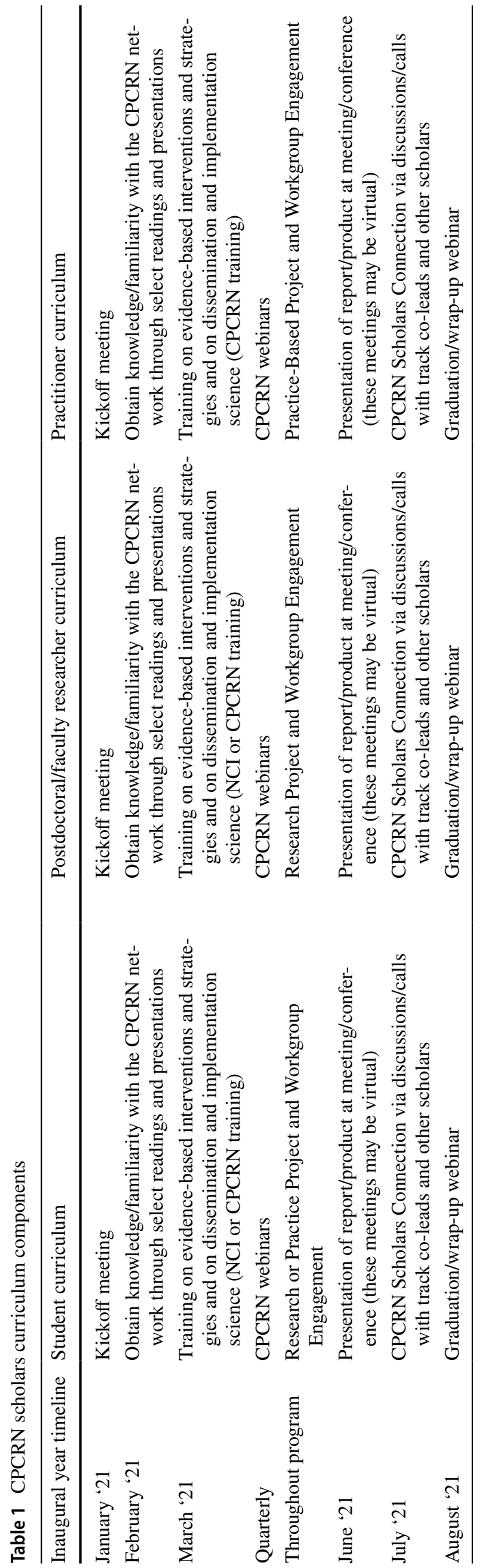

presented back to the Workgroup and the Workgroup finalized the curriculum and expectations for the first year of the Scholars program.

\section{Scholar Application and Recruitment}

Development of the scholar application form was an iterative process. A draft was presented by Workgroup co-leads to Workgroup members and feedback was incorporated. The CPCRN Coordinating Center turned the Word version of the application into an online format using Qualtrics and one of the CPCRN Collaborating Centers co-leading the Scholars Program efforts managed the data once the call for applications was released in Fall 2020. The application consisted of questions about demographics (race, ethnicity, gender), institutional affiliation, area of study/concentration, current position, how they learned about the program, names of current mentors, CPCRN workgroup of interest, proposed project, one to three goals and related activities they had for participation, and how their proposed project and goals aligned with the CPCRN strategic plan and/or logic model. Finally, applicants were asked to self-rate their competencies in D\&I science (beginner, intermediate, advanced) based on published competencies in Padek et al. [27]. The competencies focused on D\&I background knowledge, theory and approaches, study design and analysis, and practice-based considerations were used for student, postdoctoral, and faculty applicants. Practitioner applicants rated their D\&I competencies using a separate list of competencies used for the PPHEA curriculum. Data were downloaded into Microsoft Excel for descriptive analyses (frequencies, percentages). The Scholars Workgroup drafted an email call for applications which was sent to members of the CPCRN Steering Committee with a request to distribute the email and link to the electronic application form. Steering Committee members distributed the email via student listservs at their home institutions.

\section{Application Review Process}

Workgroup project co-directors assigned two reviewers to each application. The review form was guided by the scholar application questions and rated applications on the following criteria using $1=$ excellent, $2=$ fair, and $3=$ poor.

- Evidence of interest in cancer prevention and control and/ or D\&I science

- Clear, concise description of proposed project

- Clear description of the proposal goals and activities

- Feasibility of the proposed project and activities (9-month timeline for program)

- How proposed goals and activities contributed to diversity of the training program 
Table 2 Formative interview questions asked of potential scholars

Interview questions

1. Please tell me a bit about the focus of your work

2. What would you like to learn from such a training program in implementation science?

3. How would this program help with your career?

4. What deliverable(s) would you like to have at the end of this training program?

5. Might you currently have an implementation science project you are working on locally that you can engage with and/or would you be interested in joining a new project within the CPCRN?

6. How long would you like to participate in such a training program?

7. In your opinion, how large should the group of scholars be?

8. What type of mentoring would be helpful for you in this program?

9. We are interested in your ideas for how you would want to participate in the program and how you would want to connect with scholars at other CPCRN sites. Would you join in:

- Bi-monthly webinars on implementation science or career development topics? Could you tell us why or why not?

- Online discussions via Zoom? Could you tell us why or why not?

- Via discussion board for exchanges with other scholars or facilitators?

Could you tell us why or why not?

- Do you have other ideas?

10. What type of recognition would you like to receive at the end of the program, if any?

11. Are there any other ideas or comments you would like to share with us?
Probes (where applicable)

- Are you an undergraduate or graduate student? Postdoc? Faculty member? Practitioner?

- What is your cancer focus and populations of interest?

- Previous/desired experience in cancer prevention and control and/or implementation science?

- Probe: in other words, how much time would you have for this program?

O A summer?

A semester?

Up to a year?

More than one year?

- Certificate?

- Ceremony?

- Other
- Proposed work has clear fit with a CPCRN workgroup

- Proposed goals, activities, and project align well with CPCRN efforts (e.g., strategic plan, logic model)

Reviewers were also asked to provide qualitative comments, recommend two CPCRN mentors, and whether they would admit, deny, or waitlist each applicant.

\section{Results}

\section{Findings from Formative Interviews}

Interviews with 16 potential CPCRN scholars were conducted via Zoom across 4 CPCRN centers in Summer 2020 to help gather information to guide the formation of the CPCRN training program. Of the 16 interviews conducted, 4 were with assistant professors, 1 with a postdoctoral fellow, 8 with PhD students, 2 with undergraduates, and 1 with a program manager. Table 3 presents demographic data on the inaugural cohort of scholars.

The findings from the interviews informed program development. Emergent themes regarding reasons for participating in the program included individuals' desire to increase their D\&I knowledge and connect with others across the CPCRN network, produce scholarly deliverables with mentored support, and obtain skills to teach others about D\&I. Most participants indicated they would prefer the program to be 1 year in length and they were interested in mentorship focused on D\&I and cancer prevention and control research as well as professional development. This feedback guided development of the curriculum for different scholar tracks (i.e., students, researchers/faculty, and practitioners). 
Table 3 CPCRN scholars demographic data $(\mathrm{N}=20)$

\begin{tabular}{|c|c|}
\hline Categories & $\mathrm{N}(\%)$ \\
\hline \multicolumn{2}{|l|}{ School affiliation } \\
\hline Public Health & $11(55 \%)$ \\
\hline Nursing & $2(10 \%)$ \\
\hline Medicine & $6(30 \%)$ \\
\hline Liberal Arts \& Science & $1(5 \%)$ \\
\hline \multicolumn{2}{|l|}{ Highest degree earned } \\
\hline $\mathrm{PhD}$ & $7(35 \%)$ \\
\hline DNP & $1(5 \%)$ \\
\hline MD & $1(5 \%)$ \\
\hline Masters degree & $9(45 \%)$ \\
\hline Bachelors degree & $2(10 \%)$ \\
\hline \multicolumn{2}{|l|}{ Current position* (select all that apply) } \\
\hline Tenure-Track Faculty Member & $1(5 \%)$ \\
\hline Research/Clinical Faculty Member & $3(15 \%)$ \\
\hline Graduate Assistant/Graduate Research Assistant & $10(50 \%)$ \\
\hline Pre-doctoral Trainee & $3(15 \%)$ \\
\hline Post-doctoral Trainee & $3(15 \%)$ \\
\hline Research Associate/Staff & $1(5 \%)$ \\
\hline Nurse Practitioner & $1(5 \%)$ \\
\hline Nurse & $1(5 \%)$ \\
\hline Other & $1(5 \%)$ \\
\hline \multicolumn{2}{|l|}{ Gender } \\
\hline Male & $4(20 \%)$ \\
\hline Female & $16(80 \%)$ \\
\hline \multicolumn{2}{|l|}{ Race } \\
\hline White & $13(65 \%)$ \\
\hline Asian & $6(30 \%)$ \\
\hline Mexican-American & $1(5 \%)$ \\
\hline \multicolumn{2}{|l|}{ Ethnicity } \\
\hline Hispanic or Latino/Latina & $2(10 \%)$ \\
\hline Not Hispanic or Latino/Latina & $18(90 \%)$ \\
\hline \multicolumn{2}{|l|}{ Hear about the program?* (select all that apply) } \\
\hline Mentor/advisor & $16(80 \%)$ \\
\hline Listserv email & $4(20 \%)$ \\
\hline Colleague & $3(15 \%)$ \\
\hline CPCRN website & $1(5 \%)$ \\
\hline
\end{tabular}

\section{Characteristics of Inaugural Cohort of Scholars}

We received a total of 24 scholar applications. The 24 scholar applications were randomly assigned to two of nine workgroup members for review. The review criteria included interest in D\&I science and/or cancer prevention and control, details of a proposed project, specificity of proposed goals and objectives, and how the proposed work aligned with the CPCRN efforts. These nine areas were scored on a scale of 1-3 with 1-excellent, 2-fair, and 3-poor. The average scores of the 24 applications ranged from 1.06 to 3 . The cutoff for 20 scholars was 2.05 out of 3 . This cutoff was selected because there was a larger difference between the 20th and 21st application compared with the other applications. Following the scoring of the applications, scores were presented back to all Workgroup members for approval, and then Workgroup co-leads notified scholars and their primary mentors about results of the reviews. Of the 20 individuals selected for year 1 of the Scholars Program, 10 were students, 3 were postdoctoral fellows, 4 were faculty researchers, and 3 were practitioners.

We held a kickoff webinar that was held in January 2021 at which scholars met each other and received information about the program curriculum components and expectations. The scholars were presented a task management software, Trello, to help organize and stay on track with completing the assigned training components. The Trello boards were created for each of the three tracks and each scholar received access to their own board. The boards allow scholars to move curriculum items from To-do, Doing, and Completed columns. This will help monitor the progress of each scholar throughout the program. Each track has two CPCRN faculty co-leads to serve as liaisons for scholars and to help them advance through the program, troubleshoot as needed, and connect with mentors and workgroups.

\section{Baseline Application Survey Results}

The majority of scholars rated their previous D\&I experience as being at a beginner level $(n=13,65 \%)$ (Table 4). Nineteen of the 20 scholars rated themselves on the Padek et al. [27] D\&I competencies. In all section categories (definition, background, and rationale; theory and approaches; design and analysis; practice-based considerations), scholars considered themselves as beginners. The majority of scholars rated their experience as intermediate for only three competencies (determine which evidence-based interventions are worth disseminating and implementing $(\mathrm{n}=11,57.9 \%)$; describe a range of D\&I strategies, models, and frameworks $(n=12,63.1 \%)$; and describe the importance of incorporating the perspectives of different stakeholder groups $(n=12$, $63.1 \%)$ ). Only one of the scholars completed the checklist of more practice-focused competencies and ratings were "beginner" for 15 items and "intermediate" for 5 items.

\section{Program Components}

The program is self-paced with some synchronous meetings, including a kickoff meeting, planned webinars with all scholars, and a closing meeting. Scholars work on their projects and either curriculum-NCI's D\&I modules [25] or CPCRN's PPHEA program [28]. They also are invited to collaborate with a CPCRN workgroup, attend the annual CPCRN meeting, and network with other Scholars or cancer researchers (see Table 1 for curriculum). The end products 
Table 4 CPCRN scholars baseline D\&I experience and competencies

\begin{tabular}{|c|c|c|c|}
\hline \multirow[b]{2}{*}{ Overall experience $(\mathrm{N}=20)$} & \multicolumn{3}{|l|}{$\mathrm{N}(\%)$} \\
\hline & Beginner & Intermediate & Advanced \\
\hline How would you rate your overall level of experience with dissemination and implementation science? & $13(65 \%)$ & $7(35 \%)$ & $0(0 \%)$ \\
\hline Competencies $(\mathrm{N}=19)$ & Beginner & Intermediate & Advanced \\
\hline \multicolumn{4}{|l|}{ Section A: Definition, Background, and Rationale } \\
\hline A1: Define and communicate D\&I research terminology & $9(47.4)$ & $8(42.1)$ & $2(10.5)$ \\
\hline A2: Define what is and what is not D\&I research & $8(42.1)$ & $9(47.4)$ & $2(10.5)$ \\
\hline $\begin{array}{l}\text { A3: Differentiate between D\&I research and other related areas, such as efficacy research and effec- } \\
\text { tiveness research }\end{array}$ & $10(52.6)$ & $8(42.1)$ & $1(5.3)$ \\
\hline $\begin{array}{l}\text { A4: Identify the potential impact of disseminating, implementing, and sustaining effective interven- } \\
\text { tions }\end{array}$ & $7(36.8)$ & $9(47.4)$ & $3(15.8)$ \\
\hline $\begin{array}{l}\text { A5: Describe the range of expertise needed to conduct D\&I research (e.g., mixed method experience, } \\
\text { economic, organization, policy, clinical) }\end{array}$ & $11(57.9)$ & $7(36.8)$ & $1(5.3)$ \\
\hline A6: Determine which evidence-based interventions are worth disseminating and implementing & $7(36.8)$ & $11(57.9)$ & $1(5.3)$ \\
\hline $\begin{array}{l}\text { A7: Assess, describe, and quantify (where possible) the context for effective D\&I (setting characteris- } \\
\text { tics, culture, capacity and readiness) }\end{array}$ & $11(57.9)$ & $7(36.8)$ & $1(5.3)$ \\
\hline A8: Identify existing gaps in D\&I research & $12(63.1)$ & $6(31.6)$ & $1(5.3)$ \\
\hline $\begin{array}{l}\text { A9: Identify the potential impact of scaling down (aka de-implementing) an ineffective but often used } \\
\text { intervention }\end{array}$ & $16(84.2)$ & $1(5.3)$ & $2(10.5)$ \\
\hline A10: Formulate methods to address barriers of D\&I research & $15(79)$ & $2(10.5)$ & $2(10.5)$ \\
\hline \multicolumn{4}{|l|}{ Section B: Theory and Approaches } \\
\hline B1: Describe a range of D\&I strategies, models, and frameworks & $6(31.6)$ & $12(63.1)$ & $1(5.3)$ \\
\hline B2: Identify appropriate conceptual models, frameworks, or program logic for D\&I change & $11(57.9)$ & $7(36.8)$ & $1(5.3)$ \\
\hline $\begin{array}{l}\text { B3: Identify core elements (effective ingredients) or effective interventions and recognize risks of } \\
\text { making modifications to these }\end{array}$ & $13(68.4)$ & $5(26.3)$ & $1(5.3)$ \\
\hline $\begin{array}{l}\text { B4: Describe a process for designing for dissemination (planning for adoption, implementation, and } \\
\text { sustainability during the intervention development stage) }\end{array}$ & $12(63.1)$ & $7(36.8)$ & $0(0)$ \\
\hline $\begin{array}{l}\text { B5: Describe the relationships between various organization dimensions (e.g., climate, culture) and } \\
\text { D\&I research }\end{array}$ & $14(73.7)$ & $5(26.3)$ & $0(0)$ \\
\hline $\begin{array}{l}\text { B6: Explain how knowledge from disciplines outside of health (e.g., business, marketing and engineer- } \\
\text { ing) can help inform further transdisciplinary efforts in D\&I research }\end{array}$ & $12(63.1)$ & $6(31.6)$ & $1(5.3)$ \\
\hline B7: Identify and articulate the interplay between policy and organizational processes in D\&I & $16(84.2)$ & $2(10.5)$ & $1(5.3)$ \\
\hline \multicolumn{4}{|l|}{ Section C: Design \& Analysis } \\
\hline C1: Describe the core components of external validity and their relevance to D\&I research & $9(47.4)$ & $9(47.4)$ & $15.3)$ \\
\hline C2: Identify common D\&I measures and analytic strategies relevant for your research question(s) & $12(63.1)$ & $6(31.6)$ & $1(5.3)$ \\
\hline C3: Identify and measure outcomes that matter to stakeholders, adopters, and implementers & $10(52.7)$ & $7(36.8)$ & $2(10.5)$ \\
\hline $\begin{array}{l}\text { C4: Describe the application and integration of mixed-method (quantitative and qualitative) } \\
\text { approaches in D\&I research }\end{array}$ & $10(52.7)$ & $7(36.8)$ & $2(10.5)$ \\
\hline $\begin{array}{l}\text { C5: Apply common D\&I measures and analytic strategies relevant for your research question(s) within } \\
\text { your model/framework }\end{array}$ & $14(73.7)$ & $5(26.3)$ & $0(0)$ \\
\hline $\begin{array}{l}\text { C6: Identify possible methods to address external validity in study design reporting and implementa- } \\
\text { tion }\end{array}$ & $12(63.1)$ & $7(36.8)$ & $0(0)$ \\
\hline C7: List the potential roles of mediators and moderators in a D\&I study & $14(73.7)$ & $5(26.3)$ & $0(0)$ \\
\hline C8: Identify and articulate the trade-offs between a variety of different study design for D\&I research & $13(68.4)$ & $5(26.3)$ & $1(5.3)$ \\
\hline C9: Describe how to frame and analyze the context of D\&I as a complex system with interacting parts & $15(78.9)$ & $3(15.8)$ & $1(5.3)$ \\
\hline $\begin{array}{l}\text { C10: Effectively integrate the concepts of sustainability/sustainment and the rationale behind them in } \\
\text { D\&I study design }\end{array}$ & $15(78.9)$ & $3(15.8)$ & $1(5.3)$ \\
\hline C11: Describe gaps in D\&I measurement and critically evaluate how to fill them & $15(78.9)$ & $3(15.8)$ & $1(5.3)$ \\
\hline $\begin{array}{l}\text { C12: Effectively explain and incorporate concepts of de-adoption and de-implementation into D\&I } \\
\text { study design }\end{array}$ & 17 (89.5) & $2(10.5)$ & $0(0)$ \\
\hline $\begin{array}{l}\text { C13: Incorporate methods of economic evaluation (e.g., implementation costs, cost-effectiveness) in } \\
\text { D\&I study design }\end{array}$ & 15 (78.9) & $3(15.8)$ & $1(5.3)$ \\
\hline
\end{tabular}


Table 4 (continued)

\begin{tabular}{|c|c|c|c|}
\hline \multirow[b]{2}{*}{ Overall experience $(\mathrm{N}=20)$} & \multicolumn{3}{|l|}{$\mathrm{N}(\%)$} \\
\hline & Beginner & Intermediate & Advanced \\
\hline $\begin{array}{l}\text { C14: Evaluate and refine innovative scale-up and spread methods (e.g., technical assistance, interactive } \\
\text { systems, novel incentives, and "pull" strategies) }\end{array}$ & $17(89.5)$ & $2(10.5)$ & $0(0)$ \\
\hline \multicolumn{4}{|l|}{ Section D: Practice-Based Considerations } \\
\hline $\begin{array}{l}\text { D1: Describe the importance of incorporating the perspectives of different stakeholder groups (e.g., } \\
\text { patient/family, employers, payers, healthcare settings, public organizations, community, and policy } \\
\text { makers) }\end{array}$ & $4(21.1)$ & $12(63.1)$ & $3(15.8)$ \\
\hline D2: Describe the concept and measurement of fidelity & $7(36.8)$ & $11(57.9)$ & $1(5.3)$ \\
\hline D3: Articulate the strengths and weaknesses of participatory research in D\&I research & $10(52.7)$ & $8(42.1)$ & $1(5.3)$ \\
\hline D4: Determine when engagement in participatory research is appropriate with D\&I research & $13(68.4)$ & $5(26.3)$ & $1(5.3)$ \\
\hline $\begin{array}{l}\text { D5: Describe the appropriate process for eliciting input from community-based practitioners for adapt- } \\
\text { ing and intervention }\end{array}$ & $10(52.7)$ & $8(42.1)$ & $1(5.3)$ \\
\hline $\begin{array}{l}\text { D6: Identify and apply techniques for stakeholder analysis and engagement when implementing } \\
\text { evidence-based practices }\end{array}$ & $14(73.7)$ & $5(26.3)$ & $0(0)$ \\
\hline D7: Identify a process for adapting an intervention and how the process in relevant to D\&I research & $12(63.1)$ & $7(36.8)$ & $0(0)$ \\
\hline D8: Explain how to maintain fidelity of original interventions during the adaption process & $16(84.2)$ & $3(15.8)$ & $0(0)$ \\
\hline $\begin{array}{l}\text { D9: Identify sites to participate in D\&I studies and negotiate or provide incentives to secure their } \\
\text { involvement }\end{array}$ & $11(57.9)$ & $7(36.8)$ & $1(5.3)$ \\
\hline D10: Identify and develop sustainable partnerships for D\&I research & $11(57.9)$ & $8(42.1)$ & $0(0)$ \\
\hline D11: Describe how to measure successful partnerships for D\&I research & $15(78.9)$ & $4(21.1)$ & $0(0)$ \\
\hline $\begin{array}{l}\text { D12: Use evidence to evaluate and adapt D\&I strategies for specific populations, settings, contexts, } \\
\text { resources, and/or capacities }\end{array}$ & $15(78.9)$ & $3(15.8)$ & $1(5.3)$ \\
\hline
\end{tabular}

are completion of their proposed project and a project presentation.

\section{Evaluation Plan}

A CPCRN Scholars Program Evaluation Subcommittee has been formed. The evaluation of the program will employ mixed methods to understand the short-term and long-term impacts of the training program. In addition, we will evaluate specific program components. For example, we are sending electronic evaluations following educational webinars to get scholars' feedback on content, format, and speakers, and to ask them for input on future webinar focus areas. The evaluation will be informed by Kirkpatrick's model of 4 levels of training evaluation (reactions, learning, behavior, and results) [29] and will assess outcomes presented in the logic model in Fig. 1. Through the multi-component training program, the scholars will immediately improve their knowledge and skills in D\&I concepts and methodology, complete their project, and increase networking with D\&I researchers. This will lead to learning transfer to their practice, increase in grants and quality of D\&I research and practice, increased research collaborations, and an increase in the D\&I workforce. These will consequently impact D\&I cancer research and practice, and subsequently cancer incidence and health inequities. At the end of the program, all scholars will complete an immediate post-test that will evaluate the program components, discuss strategies for learning transfer to their training or jobs, and provide them with the opportunity to make suggestions for improvements. We will interview selected scholars to learn about their experience, the benefits of the program, integration of D\&I into and completion of their projects, and how they are applying their knowledge and skills. We will conduct annual surveys with program alumni for 3 years to evaluate the continued use of the training content, and track products and deliverables emerging from the program and beyond, and progress in their D\&I journey.

\section{Discussion}

The CPCRN Scholars Program is the first CDC-funded network to establish a formal scholars program for three groups-students, postdoctoral fellows/researchers, and practitioners. Development of the program components and processes was guided by prior work of the CDC-funded HBRN's student scholars program [23]. The intention of the Scholars Workgroup was not to recreate the wheel and duplicate existing programs such as the NCI-sponsored TIDRIC or TIDIHR programs $[15,30]$ but to incorporate open-access components into a broad, self-paced curriculum specifically for the CPCRN network. The ultimate goal is to grow the pipeline of scholars through the CPCRN network that often 


\section{Outcomes}

Inputs

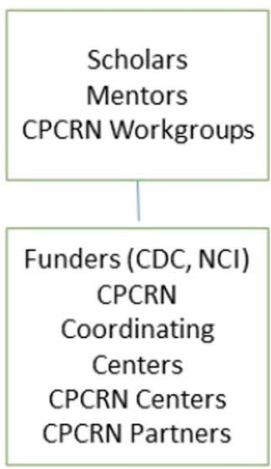

Activities

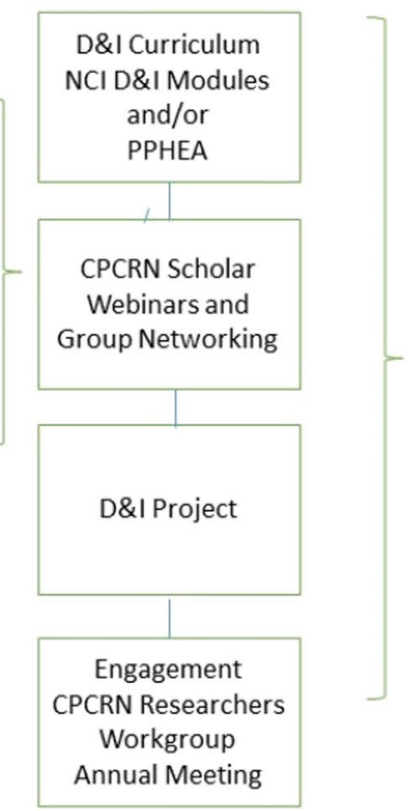

Short-term

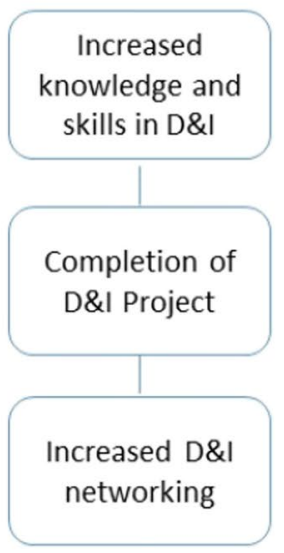

Intermediate

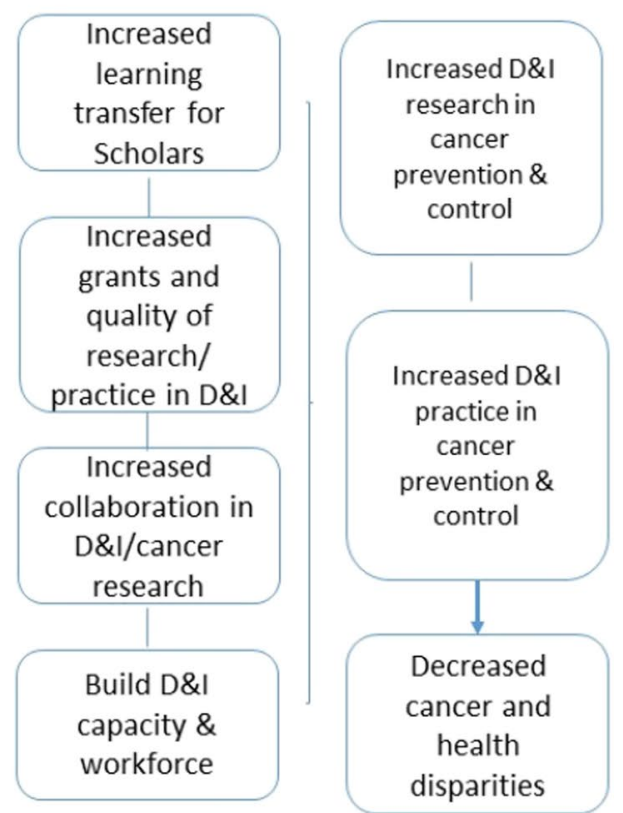

Fig. 1 Logic model for the evaluation of the CPCRN Scholars Program

involves students, researchers, and practitioner partners in D\&I work but not in a formal manner. The success of program development can be attributed in large part to the input from potential scholars during the formative interview process and from recommendations and collaborations with network experts, affiliates, and federal agency partners.

The CPCRN Scholars Workgroup has learned greatly from the development of the program and launch that will be helpful for future program years and for other similar D\&I, capacity-building training programs. First, we kept our outreach efforts within the CPCRN network for the first year of the program in order to keep the cohort size manageable. CPCRN sites were asked to recruit scholars through their institution listservs; thus, we had a greater response from students and researchers/faculty members compared with practitioners. It has been reported elsewhere that capacity of such practitioner-focused trainings is limited and the trainings may not be feasible for or meet the needs of intended provider implementers [9]. Moving forward, we will make a more concerted and targeted effort to recruit practitioner scholars and this will be done with the support of CPCRN center partners and federal agency partners conducting work in capacity building for cancer prevention and control.

Second, we will be more intentional in recruiting a diverse cohort of scholars from underrepresented minority groups. Reducing cancer-related health disparities in pursuit of health equity will require purposeful efforts, particularly in D\&I training, including increasing the minority scholar workforce in our cancer prevention and control work and diversifying research participants. Training scholars in culturally relevant methods and programming is critically needed if we are to make a significant impact on reducing health disparities [31]. Training programs that address barriers or purposefully recruit marginalized researchers within medicine and biomedical research $[32,33]$ demonstrate participant success and reduction in disparities among underrepresented communities. We also plan to consider race and/ or gender matching of scholars and mentors which was not conducted in this inaugural year.

Third, while we asked applicants to include names of primary and secondary mentors in their application, we did not specify roles of the scholar mentors upfront. For the next round of the CPCRN Scholars Program, we will describe a clearer role for mentors (e.g., guide progress through the curriculum, help connect scholars with CPCRN workgroups) upfront during the application process and once scholars are selected for participation. Finally, disseminating our call for applications was slightly delayed given the COVID-19 pandemic and so the inaugural cohort will have 9 months to complete the program. For the next cohort, we will release the call for applications prior to the start of the grant year so that scholars have a full year to complete the training. Guided by input from grant network collaborators and the inaugural cohort of scholars and mentors, the 
CPCRN Scholars Program looks forward to sustaining this initiative and impacting the D\&I knowledge and skills of its colleagues in training.

The CPCRN Scholars Program is a multi-component training program to increase knowledge and skills related to D\&I for cancer control. The program will train students through researchers and build the pipeline of translational researchers and enhance the capacity of practitioners working in cancer control. Evaluation of the program will inform program strengths and weaknesses, learning transfer, and integration of D\&I concepts into their practices. Ultimately, the program hopes to catalyze D\&I research across the USA and have results that will impact cancer-related health disparities.

Funding This publication is supported by the Centers for Disease Control and Prevention of the US Department of Health and Human Services (HHS) as part of financial assistance awards (U48 DP006401; U48 DP006377) totaling \$599,998 with 100 percent funded by CDC/ HHS. The contents are those of the authors and do not necessarily represent the official views of, nor an endorsement by, $\mathrm{CDC} / \mathrm{HHS}$ or the US government.

\section{References}

1. Mariotto AB, Yabroff KR, Shao Y, Feuer EJ, Brown ML (2011) Projections of the cost of cancer care in the United States: 2010 2020. J Natl Cancer Inst 103(2):117-128

2. Trimble EL, Rajaraman PL, Chao A, Gross T, Levin C, Qiao YL, Rebbeck T, Stevens L, Zhao F (2015) Need for national commitments to cancer research to guide public health investment and practice, in Cancer: disease control priorities, third edition (volume 3). H Gelband et al. (Eds). Washington, DC, The International Bank for Reconstruction and Development / The World Bank

3. Balas EA, Boren SA (2000) Managing clinical knowledge for health care improvement. Yearb Med Inform 1:65-70

4. Brownson RC, Colditz GA, Dobbins M, Emmons KM, Kerner JF, Padek M, Proctor EK, Stange KC (2015) Concocting that magic elixir: successful grant application writing in dissemination and implementation research. Clin Transl Sci 8(6):710-716

5. Shea CM, Young TL, Powell BJ, Rohweder C, Enga ZK, Scott JE, Carter-Edwards L, Corbie-Smith G (2017) Researcher readiness for participating in community-engaged dissemination and implementation research: a conceptual framework of core competencies. Transl Behav Med 7(3):393-404

6. Tabak RG, Padek MM, Kerner JF, Stange KC, Proctor EK, Dobbins MJ, Colditz GA, Chambers DA, Brownson RC (2017) Dissemination and implementation science training needs: insights from practitioners and researchers. Am J Prev Med 52(3 Suppl 3):S322-S329

7. Eccles MP, Mittman BS (2006) Welcome to implementation science. Implement Sci 1(1). https://doi.org/10.1186/1748-5908-1-1

8. Peters DH, Tran NT, Adam T, Alliance for Health Policy and Systems Research, World Health Organization (2013) Implementation research in health: a practical guide. https://www.who.int/alliancehpsr/resources/implementationresearchguide/en/. Accessed April 1,2021
9. Ginossar T, Heckman CJ, Cragun D, Quintiliani LM, Proctor EK, Chambers DA, Skolarus T, Brownson RC (2018) Bridging the chasm: challenges, opportunities, and resources for integrating a dissemination and implementation science curriculum into medical education. J Med Educ Curric Dev 5. https://doi.org/10.1177/ 2382120518761875

10. Karlin BE, Brown GK, Jager-Hyman S, Green KL, Wong M, Lee DS, Bertagnolli A, Ross TB (2019) Dissemination and implementation of cognitive behavioral therapy for depression in the Kaiser Permanente Health Care System: evaluation of initial training and clinical outcomes. Behav Ther 50(2):446-458

11. Resnick B, Carrico R, Gravenstein S, Hogue MD, Middleton DB, Rehm S, Schaffner W, Tan L (2018) Dissemination and implementation of the ICAMP. Transl Behav Med 8(6):867-875

12. Ben-David K Lin JJ, Ferrara JLM, Gabrilove JL (2021) Tisch Cancer Institute Scholars Program: mentored cancer research training pipeline for medical students. J Cancer Educ 1-6. https://doi.org/ 10.1007/s13187-020-01934-8

13. Brownson RC, Jacob RR, Chambers DA, Colditz GA, Emmons KM, Haire-Joshu D, Kerner JF, Padek M, Pfund C, Sales A (2021) Building the next generation of researchers: mentored training in dissemination and implementation science. Acad Med 96(1):86-92

14. Jacob RR, Gacad A, Padek M, Colditz GA, Emmons KM, Kerner JF, Chambers DA, Brownson RC (2020) Mentored training and its association with dissemination and implementation research output: a quasi-experimental evaluation. Implement Sci 15(1):30

15. Meissner HI, Glasgow RE, Vinson CA, Chambers S, Brownson RC, Green LW, Ammerman AS, Weiner BJ, Mittman B (2013) The US training institute for dissemination and implementation research in health. Implement Sci 8:12

16. Gonzales R, Handley MA, Ackerman S, O'Sullivan PS (2012) A framework for training health professionals in implementation and dissemination science. Acad Med 87(3):271-278

17. Padek M, Mir N, Jacob RR, Chambers DA, Dobbins M, Emmons KM, Kerner J, Kumanyika S, Pfund C, Proctor EK, Stange KC, Brownson RC (2018) Training scholars in dissemination and implementation research for cancer prevention and control: a mentored approach. Implement Sci 13(1):18

18. Chambers DA, Proctor EK, Brownson RC, Straus SE (2017) Mapping training needs for dissemination and implementation research: lessons from a synthesis of existing D\&I research training programs. Transl Behav Med 7(3):593-601

19. Davis R, D'Lima D (2020) Building capacity in dissemination and implementation science: a systematic review of the academic literature on teaching and training initiatives. Implement Sci 15(1):97

20. Paskett ED, Pennell ML, Ruffin MT, Weghorst CM, Lu B, Hade EM, Peng J, Bernardo BM, Wewers ME (2020) A multi-level model to understand cervical cancer disparities in Appalachia. Cancer Prev Res 13(3):223-228

21. Ramanadhan S, Davis MM, Armstrong R, Baquero B, Ko LK, Leng JC, Salloum RG, Vaughn NA, Brownson RC (2018) Participatory implementation science to increase the impact of evidence-based cancer prevention and control. Cancer Causes Control 29(3):363-369

22. Cancer Prevention and Control Research Network. https://cpcrn. org/about-cpcrn. Accessed April 1, 2021

23. Croff R, Tang W, Friedman DB, Balbim GM, Belza B (2020) Training the next generation of aging and cognitive health researchers. Gerontol Geriatr Educ 1-17. https://doi.org/10.1080/ 02701960.2020 .1824912

24. Mainor AG, Decosimo K, Escoffery C, Farris P, Shannon J, Winters-Stone K, Williams B, Leeman J (2018) Scaling up and tailoring the "Putting Public Health in Action" training curriculum. Health Promot Pract 19(5):664-672 
25. National Cancer Institute. Training Institute for Dissemination and Implementation Research in Cancer (TIDIRC) OpenAccess. https://cancercontrol.cancer.gov/is/training-education/TIDIRCopen-access. Accessed April 1, 2021

26. Patton MQ (2014) Qualitative research \& evaluation methods: integrating theory and practice, 4 th edn. Sage Publications, Thousand Oaks

27. Padek M, Colditz G, Dobbins M, Koscielniak N, Proctor EK, Sales AE, Brownson RC (2015) Developing educational competencies for dissemination and implementation research training programs: an exploratory analysis using card sorts. Implement Sci 10:114

28. Cancer Prevention and Control Research Network. Putting Public Health Evidence in Action. https://cpcrn.org/training. Access April 1, 2021

29. Kirkpatrick JD, Kayser Kirkpatrick W (2016) Kirkpatrick's four levels of training evaluation. Association for Talent Development Press, Alexandria

30. Vinson CA, Clyne M, Cardoza N, Emmons KM (2019) Building capacity: a cross-sectional evaluation of the US Training Institute for Dissemination and Implementation Research in Health. Implement Sci 14(1):97
31. Jackson CS, Gracia JN (2014) Addressing health and health-care disparities: the role of a diverse workforce and the social determinants of health. Public Health Rep 129(Suppl 2):57-61

32. Crews DC, Wilson KL, Sohn J, Kabacoff CM, Poynton SL, Bolz J, Wolfe A, White PT, Will C, Collins C, Gauda E, Robinson DN (2020) Helping scholars overcome socioeconomic barriers to medical and biomedical careers: creating a pipeline initiative. Teach Learn Med 32(4):422-433

33. Foroozesh M, Giguette M, Morgan K, Johanson K, D'Amour G, Coston T, Wilkins-Green C (2017) Building integrated pathways to independence for diverse biomedical researchers: Project Pathways, the BUILD program at Xavier University of Louisiana. BMC Proc 11(Suppl 12):28

Publisher's Note Springer Nature remains neutral with regard to jurisdictional claims in published maps and institutional affiliations. 